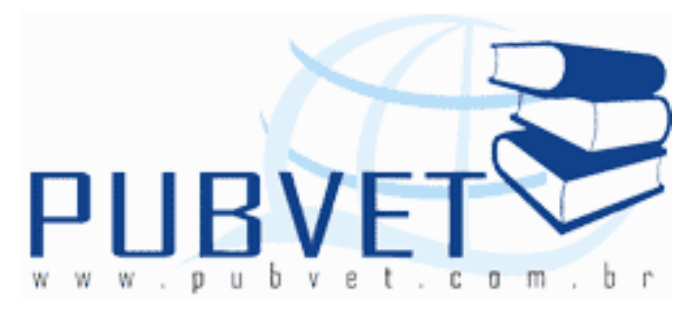

PUBVET, Publicações em Medicina Veterinária e Zootecnia.

\title{
Avaliação do potencial reservatório do cão na Leishmaniose Visceral em dois municípios do Estado do Ceará
}

Marlos Medeiros Chaves ${ }^{1}$, Maria Jânia Teixeira², Margarida Maria Lima Pompeu², Raimundo Nonato Sousa ${ }^{3}$, José Wellington Oliveira Lima ${ }^{4}$

1 Mestre em Patologia, Universidade Federal do Ceará (UFC);

2 Doutor em Patologia Humana, Professor Adjunto da UFC;

3 Entomologista, Fundação Nacional de Saúde (FUNASA);

4 Doutor em Saúde Pública, Professor Adjunto da Universidade Estadual do Ceará (UECE).

\section{Resumo}

Este estudo teve o objetivo de avaliar o potencial reservatório do cão na leishmaniose visceral (LV), bem como identificar os possíveis sinais clínicos mais freqüentes associados à infectividade e soropositividade. Cães com sorologia positiva $(n=38)$ e negativa $(n=11)$ para o teste de ELISA foram submetidos a experimentos de xenodiagnóstico a fim de se determinar a infectividade para o inseto vetor Lutzomyia longipalpis. Foi observado infectividade para o Lu. longipalpis em $36,84 \%$ (14) dos cães do grupo de soropositivos e nenhum dos soronegativos $(p<0,05)$. Os sinais clínicos de emagrecimento e onicogrifose mostraram estar associados com soropositividade e infectividade. Cães mais jovens ( $<3$ anos) infectaram flebótomos com uma freqüência mais elevada. Estes resultados confirmam a importância do cão na epidemiologia da LV como 
fonte de infecção para o flebótomo e indicam que os sinais clínicos de emagrecimento, onicogrifose e idade são um forte indicativo do potencial de infectividade.

Palavras-chave: Leishmaniose Visceral Canina; Infectividade; Reservatório; Sinais Clínicos; Xenodiagnóstico.

\title{
Evaluation of the potential reservoir dog in Visceral Leishmaniasis in two municipalities of the State of Ceará
}

\begin{abstract}
This study had the objective of evaluating the reservoir potential of the dog in visceral leishmaniasis $(\mathrm{VL})$ besides to identify the possible more frequent clinical signs associated to the infectiousness and seropositiveness. Dogs with positive $(n=38)$ and negative $(n=11)$ for the serological ELISA test were studied through xenodiagnosis experiments to determine the infectiousness to phlebotomine vector Lutzomyia longipalpis. Infectiousness for Lu. longipalpis was observed in $36,84 \%$ (14) of the dogs from seropositive group and none of the seronegative $(p<0.05)$. The clinical signs loss of weight and onychogryphosis showed to be associated with seropositiveness and infectiousness. Younger dogs ( $<3$ years) infected sand flies with a higher frequency. These results confirm the importance of the dog in the epidemiology of VL as infection source for the sand fly and they indicate that the clinical signs loss of weight, onychogryphosis and age are a strong indicative of the dogs infectiousness potential.
\end{abstract}

Keywords: Canine Visceral Leishmaniasis; Infectiousness; Reservoir; Clinical signs; Xenodiagnosis.

\section{INTRODUÇÃO}

A leishmaniose visceral (LV), também conhecida como calazar, é uma zoonose que pode afetar o homem causando um quadro sistêmico e grave. É causada por protozoários tripanossomatídeos do gênero Leishmania pertencentes ao complexo donovani. No Brasil, a LV tem como agente etiológico 
a Leishmania (Leishmania) chagasi e é transmitida, principalmente por fêmeas de flebotomíneos da espécie Lutzomyia longipalpis (Diptera, Psychodidae). Nas regiões rurais, os hospedeiros silvestres conhecidos são as raposas (Dusicyon vetulus e Cerdocyon thous) e marsupiais (Didelphis albiventris) enquanto que nas áreas urbanas, o cão (Canis familiaris) é a principal fonte de infecção (GONTIJO \& MELO, 2004; MINISTÉRIO DA SAÚDE, 2006).

No Brasil, desde os estudos de FERREIRA et al. (1938) e CHAGAS (1940) ficou demonstrado o papel do cão como reservatório da LV. No Ceará, os primeiros achados de cães infectados foram feitos por Deane (DEANE \& DEANE, 1954). Baseado nos conhecimentos sobre a cadeia de transmissão da LV, O Ministério da Saúde do Brasil desenvolveu um programa de controle que teve início em 1953, quando surgiram numerosos casos da doença (DEANE, 1958). A estratégia de controle incluía a eliminação de cães infectados e o controle do vetor através da aplicação de inseticidas de efeito residual. Nos anos que se seguiram, a prioridade do Ministério foi o aumento da cobertura do Programa de Controle, com a expectativa de que uma intervenção abrangente e de qualidade, teria como resultado o controle da LV (MONTEIRO et al., 1994). Nesse sentido, diversos estudos foram realizados em importantes áreas endêmicas de LV através de inquéritos sorológicos de massa com o intuito de medir a prevalência da doença canina e posteriormente o impacto da eliminação daqueles soropositivos, confirmando o envolvimento e a importância do cão. (MAGALHÃES et al., 1980; LACERDA, 1994; BRAGA et al., 1998; PALATNIK DE SOUSA et al., 2001).

Tendo em vista a participação do cão como principal reservatório da LV em áreas urbanas, é extremamente necessário o diagnóstico correto da Leishmaniose Visceral Canina (LVC) (GRADONI, 2002). Usualmente o diagnóstico da LV baseia-se na utilização de técnicas sorológicas (reação de imunofluorescência indireta-RIFI e ensaio imunoenzimático-ELISA) que apresentam baixas taxas de sensibilidade e especificidade (DE PAULA et al., 2003). Clinicamente, o diagnóstico dos cães infectados que representariam um risco imediato de transmissão ao flebotomíneo seria extremamente 
importante. Entretanto, devido ao amplo espectro de sinais clínicos que podem ser observados, é muito difícil de ser feito. Em alguns estudos com ênfase na sintomatologia do cão com LVC, podemos observar a freqüência de sinais como perda de peso, onicogrifose, exulcerações, adinamia, alopecia, lifadenopatia e lesão ocular nos cães analisados (ALENCAR, 1963; LANOTTE et al., 1979, MARZOCHI et al., 1985; ABRANCHES et al., 1991; CIAMARELLA et al., 1997). Contudo, dependendo da fase da doença, estes podem inclusive não manifestar qualquer sintoma (BERRAHAL et al., 1996; GONTIJO \& MELO, 2004).

Considerando que a condição para a manutenção do ciclo da doença o hospedeiro demonstre habilidade de transmissão para o vetor, observamos dados controversos na literatura com relação ao real potencial infectivo dos cães. MOLINA et al. (1994) e GUARGA et al (2000) demonstraram que as taxas de infecção dos flebótomos não estão correlacionadas com as condições clínicas dos animais, ou seja, cães assintomáticos teriam a mesma capacidade infectiva que os cães oligossintomáticos e polissintomáticos. Alguns estudos estimam que mais de $50 \%$ dos cães soropositivos capazes de infectar vetores identificados em inquéritos de campo seriam assintomáticos (SIDERIS et al., 1999, ALMEIDA et al., 2009; BARBOSA et al., 2010). Por outro lado, TRAVI et al. (2001), ALMEIDA et et. (2005) e VERÇOSA et al. (2008) demonstraram existir uma correlação positiva entre a presença de sintomas e infectividade para flebótomos.

A questão epidemiológica decisiva é saber se cães positivos para a LVC pelas técnicas de diagnóstico tradicionais são também infectivos para flebotomíneos. Esta informação poderia nos dar o melhor valor da carga infectiva de uma população canina em uma área endêmica (GRADONI, 1999).

$O$ entendimento dos mecanismos envolvidos no controle do reservatório canino na LV envolve vários aspectos, entre eles, o conhecimento da infectividade para a Lu. longipalpis. Neste trabalho, investigamos a capacidade de uma amostra de cães soropositivos para a L.(L.) chagasi infectar flebotomíneos Lu. longipalpis através da técnica de xenodiagnóstico, além de identificar os sinais e sintomas que estão associados à infectividade. 


\section{MATERIAL E MÉTODOS}

Seleção dos cães. Os cães incluídos neste estudo foram oriundos de uma população que foi submetida a ciclos sucessivos de eliminação nas localidades Telha (povoado), Telha (sítio), Santa Maria e Camará, pertencentes ao município de Aquiraz ( $35 \mathrm{~km}$ de distância da cidade de Fortaleza) e da localidade Gereraú, município de Itaitinga (33km de Fortaleza). Essas regiões são caracterizadas por apresentarem a ocorrência de focos de LVC em inquéritos epidemiológicos preliminares realizados pelo trabalho de rotina do Programa de Controle da Leishmaniose da Fundação Nacional de Saúde-Funasa (documento interno). Foram selecionados 49 cães.

ELISA (Enzime Linked Immunosorbent Assay). Objetivando determinar os cães que poderiam fazer parte do estudo, foi estabelecida uma rotina semanal de triagem pelo teste de ELISA para o imunodiagnóstico de calazar (BADARÓ et al., 1986; MOHAMMED et al., 1985). Os testes foram realizados no laboratório de Parasitologia do Núcleo de Medicina Tropical Prof. Joaquim Eduardo de Alencar da Universidade Federal do Ceará, seguindo a técnica proposta por EVANS et al. (1990). Os soros para utilização no teste foram obtidos através de centrifugação de $5 \mathrm{~mL}$ de sangue endovenoso retirado da pata anterior de cada cão. Os valores positivos foram aqueles maiores a 3 desvios padrões acima da média dos controles negativos. Ao longo de 1 ano, foram examinados nestas áreas 713 cães, sendo que 157 apresentaram positividade para a ELISA. Foram selecionados 38 cães soropositivos escolhidos aleatoriamente além de 11 cães soronegativos que tinham a característica de pertencer à mesma casa ou no máximo à mesma quadra dos cães soropositivos.

Captura dos flebótomos matrizes. Os flebótomos matrizes foram coletados no sítio Raposa, localidade situada no município de Baturité ( $95 \mathrm{~km}$ de Fortaleza). No deslocamento da equipe de campo e transporte de material foi utilizada viatura pertencente à Funasa. O objetivo era a captura de espécimes de Lu. longipalpis, vetor da L. (L.) chagasi. 
Colonização. Após as capturas e retorno para Fortaleza, os flebótomos foram colonizados segundo o método KILLICK-KENDRICK et al. (1977) e KILLICK-KENDRICK \& KILLICK-KENDRICK (1991).

Diagnóstico Clínico. O exame clínico dos cães, realizado momentos antes do início do experimento de xenodiagnóstico, considerou os seguintes aspectos: idade, sexo, raça, lesões externas, alopecia, adinamia, perda de peso e unhas de tamanho e formatos anormais. Os critérios utilizados na análise clínica dos cães foram baseados no estudo proposto por POZIO et al. (1981).

Xenodiagnóstico. Foram constituídos dois grupos de estudo: um grupo formado por 38 cães com teste ELISA positivo e um grupo com 11 cães ELISA negativo. Ao longo do experimento, o grupo ELISA positivo sofreu algumas variações com relação a área do corpo exposta e ao número de flebótomos. Essas variações foram caracterizadas em 3 subgrupos ELISA positivo: 18 cães, onde foram utilizados 50 flebótomos fêmeas para cada cão e com exposição restrita somente à região da cabeça; 10 cães, utilizando 50 flebótomos fêmea e exposição de todo o corpo do animal; 10 cães, utilizando 100 flebótomos fêmea e exposição de todo o corpo do animal. Nos 11 cães ELISA negativo, utilizou-se 50 flebótomos fêmea e exposição restrita somente à região da cabeça. Flebótomos machos foram também utilizados na proporção de 1:5 fêmeas, tendo em vista o seu efeito estimulante no repasto sanguíneo (KELLY \& DYE, 1997).

As gaiolas para a exposição da cabeça do cão eram de armação metálica $(40 \times 40 \times 40 \mathrm{~cm})$ com tela em tecido e para a exposição do corpo todo, foram utilizadas tendas armadas $(1,80 \mathrm{~m}$ de altura $\times 1,20 \mathrm{~m}$ de largura $\mathrm{e}$ comprimento) com tela em tecido. A captura dos flebótomos no interior da tenda foi feita utilizando capturador de Castro.

Os cães foram anestesiados via intramuscular através da utilização do anestésico cloridrato de cetamina $(10 \mathrm{mg} / \mathrm{kg})$ associado a cloridrato de xylazina $(2 \mathrm{mg} / \mathrm{kg})$, sendo administrados 10 minutos antes, sulfato de atropina $(0,05 \mathrm{mg} / \mathrm{kg})$. A dosagem dos anestésicos era administrada novamente após 50 minutos da primeira dose, a fim de prevenir que os cães acordassem durante 0 
experimento. A duração de cada experimento de xenodiagnóstico foi de 1 hora e 30 minutos e tinha início às 18:00h.

Dissecção dos flebótomos. Sete dias após o xenodiagnóstico, os flebótomos fêmea de Lu. longipalpis foram imobilizados e dissecados em uma gota de solução salina. Com o auxílio de um microscópio estereoscópico, o trato digestivo foi isolado utilizando agulhas de seringas de insulina. Em seguida uma lâmina foi montada e examinada em microscópio ótico com aumentos de 10X e 40X objetivando a observação de promastigotas de L.(L.) chagasi.

Análises estatísticas. Proporções foram comparadas através do Teste Exato de Fisher, por que praticamente todas as tabelas de contingências apresentavam células com valor esperado menor que 5 . A distribuição do número de fêmeas de Lu. longipalpis infectadas segundo a presença/ausência de sinais ou sintomas, foram comparadas através do Teste não Paramétrico de Mann-Whitney. As proporções ou distribuições cujas comparações produziram probabilidades da hipótese nula ser verdadeira (Valor-p) iguais ou inferiores a 0,05 foram consideradas significativamente diferentes.

\section{RESULTADOS}

Inicialmente, foi avaliado a infectividade dos cães segundo o resultado do exame sorológico. Dos 38 cães escolhidos para o exame de xenodiagnóstico, $14(36,84 \%)$ foram infectivos a Lu. longipalpis. Por outro lado, nenhum cão com sorologia negativa infectou os flebótomos. Esta diferença foi estatisticamente significativa (Tabela 1). 
TABELA 1- Infectividade para a Lu. longipalpis dos cães estudados, de acordo com o exame sorológico ELISA.

\begin{tabular}{lcccc}
\hline Resultado do & Total & \multicolumn{2}{c}{ Cães } & Valor- p \\
Exame Sorológico & & \multicolumn{2}{c}{ Infectantes } & \\
& & $\mathbf{N}$ & $\%$ & \\
\hline Soropositivo & 38 & 14 & $36,84 \%$ & \\
Soronegativo & 11 & 0 & 0,00 & $\mathbf{0 , 0 2 1}$ \\
\hline Total & 49 & 14 & 28,57 & - \\
\hline
\end{tabular}

Com o objetivo de identificar marcadores clínicos de infectividade do cão, mediu-se a associação entre sinais clínicos e a capacidade do cão com sorologia positiva de infectar ou não fêmeas de Lu. longipalpis (Tabela 2). Os cães que apresentavam emagrecimento, onicogrifose e idade inferior a 3 anos de idade, infectaram os flebótomos com uma freqüência significativamente mais elevada do que aqueles que não apresentavam estas características. No entanto, a presença de exulceração, alopecia, a ocorrência de adinamia e raça do cão, não estavam significativamente associadas à capacidade do cão de infectar o vetor.

Mediu-se também a intensidade de infecção de fêmeas de $L u$. longipalpis, segundo a ocorrência de sinais e sintomas de cães com sorologia positiva (Tabela 3). Os cães que apresentavam emagrecimento e onicogrifose infectaram um número significativamente maior de flebótomos que aqueles que não apresentavam os referidos sintomas. Da mesma forma, os cães mais novos (idade < 3 anos) e mestiços, também infectaram um maior número de flebótomos, embora estas diferenças não sejam significativas. Entretanto a ocorrência de exulceração, alopecia e adinamia não estavam associadas a um maior número de flebótomos infectados. 
TABELA 2- Infectividade para a Lu. longipalpis, de cães portadores de anticorpos anti-Leishmania, de acordo com os sintomas clínicos e outras condições.

Sinais Clínicos e outras

Condições

\section{Total}

Cães

Valor- p

Infectantes

$\mathrm{N}$

$\%$

\begin{tabular}{llcccc}
\hline Emagrecimento & Não & 17 & 3 & 17,65 & \\
Onicogrifose & Sim & 21 & 11 & 52,38 & $\mathbf{0 , 0 4 3}$ \\
& Não & 24 & 4 & 16,67 & \\
Exulceração & Sim & 14 & 10 & 71,43 & $\mathbf{0 , 0 0 1}$ \\
& Não & 21 & 8 & 38,10 & \\
Adinamia & Sim & 17 & 6 & 35,29 & 1,000 \\
Alopecia & Não & 28 & 9 & 32,14 & \\
& Sim & 10 & 5 & 50,00 & 0,449 \\
Idade & Não & 19 & 5 & 26,32 & \\
\multirow{2}{*}{ Mestiço } & Sim & 19 & 9 & 47,37 & 0,313 \\
Vira-lata & $\geq \mathbf{3}$ anos & 11 & 1 & 9,09 & \\
\hline & $<\mathbf{3}$ anos & 27 & 13 & 48,15 & $\mathbf{0 , 0 3 0}$ \\
& & 25 & 12 & 48,00 & \\
& & 13 & 2 & 15,38 & 0,077 \\
\hline
\end{tabular}


TABELA 3- Distribuição do número de Lu. longipalpis infectadas em cães $(\mathrm{N}=38)$ portadores de anticorpos anti-Leishmania, de acordo com os sintomas clínicos e outras condições.

\begin{tabular}{llcc}
\hline Sinais Clínicos e Outras Condições & Média & Valor- p \\
\hline Emagrecimento & Não & 2,29 & \\
& Sim & 12,19 & $\mathbf{0 , 0 2 0}$ \\
Onicogrifose & Não & 4,18 & \\
& Sim & 13,91 & $\mathbf{0 , 0 0 2}$ \\
Exulceração & Não & 8,49 & \\
\multirow{2}{*}{ Adinamia } & Sim & 6,86 & 0,734 \\
\multirow{2}{*}{ Alopecia } & Não & 6,27 & \\
& Sim & 11,93 & 0,292 \\
Idade & Não & 5,02 & \\
& Sim & 10,50 & 0,182 \\
Mestiço & $\geq \mathbf{3}$ anos & 4,06 & \\
Vira-lata & $<\mathbf{3}$ anos & 9,27 & 0,055 \\
\hline
\end{tabular}

$\mathrm{Na}$ perspectiva de identificar marcadores clínicos de positividade sorológica, medimos a associação entre sinais clínicos e o resultado da sorologia (Tabela 4). Observamos um percentual significativamente maior de cães soropositivos entre aqueles que apresentavam emagrecimento, onicogrifose e de raça mestiça. Por sua vez, a presença de exulceração e alopecia e a idade do cão não estavam associados a uma maior freqüência de soropositividade. 
TABELA 4- Soropositividade de cães $(\mathrm{N}=38)$, de acordo com os sintomas clínicos e outras condições.

\begin{tabular}{llcccc}
\hline Sinais Clínicos e outras & Total & \multicolumn{2}{c}{ Cães } & Valor- p \\
Condições & & \multicolumn{4}{c}{ Soropositivos } \\
& & & N & $\%$ & \\
\hline Emagrecimento & Não & 27 & 17 & 62,96 & \\
& Sim & 22 & 21 & 95,45 & $\mathbf{0 , 0 1 3}$ \\
Onicogrifose & Não & 35 & 24 & 68,57 & \\
& Sim & 14 & 14 & 100,00 & $\mathbf{0 , 0 2 1}$ \\
Exulceração & Não & 30 & 21 & 70,00 & \\
& Sim & 19 & 17 & 89,47 & 0,165 \\
Adinamia & Não & 38 & 28 & 73,68 & \\
\multirow{3}{*}{ Alopecia } & Sim & 11 & 10 & 90,91 & 0,415 \\
& Não & 28 & 19 & 67,86 & \\
Idade & Sim & 21 & 19 & 90,48 & 0,087 \\
& $\geq \mathbf{3}$ anos & 15 & 11 & 73,33 & \\
Mestiço & $<\mathbf{3}$ anos & 34 & 27 & 79,41 & 0,716 \\
Vira-lata & & 28 & 25 & 89,29 & \\
\hline
\end{tabular}

Observamos que tecnicamente é mais fácil realizar um xenodiagnóstico expondo somente a cabeça do cão em vez do corpo todo. Porém, é preciso ter certeza que ambas as técnicas fornecem resultados semelhantes no que diz respeito à ocorrência de infecção dos flebótomos (Tabela 5). Quando foi exposta apenas a cabeça dos cães, obtivemos um percentual mais elevado de experimentos nos quais pelo menos uma fêmea de Lu. longipalpis havia se infectado, embora esta diferença não seja significativa (valor $=0,104)$. 
TABELA 5- Infectividade para a Lu. longipalpis, de acordo com a área do corpo exposta aos flebótomos.

\begin{tabular}{|c|c|c|c|c|}
\hline Área do corpo exposta aos & Total & Cães & antes & Valor- p \\
\hline flebótomos & & $\mathbf{N}$ & $\%$ & \\
\hline Somente a Cabeça & 18 & 9 & 50 & \\
\hline Todo o Corpo & 20 & 5 & 25 & $0,104^{*}$ \\
\hline
\end{tabular}

$¥$ Teste exato de Fisher: Valor- $p=0,104$

\section{DISCUSSÃO}

A identificação dos elos da cadeia epidemiológica das doenças transmitidas por vetores é essencial para desenhar estratégias efetivas de controle. Mais do que isso, necessitamos conhecer a importância relativa de cada componente e de seu grau de susceptibilidade a possíveis intervenções.

A competência reservatória do cão está diretamente relacionada com a acessibilidade dos flebótomos vetores às leishmanias no organismo do animal. Portanto, um resultado significativo de cães infectantes aos vetores revela um elevado parasitismo cutâneo. É reconhecido o intenso parasitismo da pele na LVC (DEANE \& DEANE, 1954; MARZOCHI et al., 1985; VERÇOSA, et al., 2008; LIMA et al., 2010).

Em nosso estudo inicialmente documentamos um número significativo de cães com sorologia positiva com a capacidade de infectar flebótomos $(36,84 \%)$, o que reforça o papel importante deste animal como hospedeiro reservatório da LV no Brasil. Esta proporção poderia ser ainda maior, pois devemos considerar que os cães deste estudo não se encontravam na mesma fase da doença, caracterizando assim, uma amostra heterogênea com relação ao parasitismo cutâneo no animal. Outro fator que devemos observar é que o xenodiagnóstico, apesar de ser uma técnica de reconhecida especificidade, possui baixa sensibilidade por depender de fatores que vão do transporte até a dessecação dos insetos. É muito importante também observar que cão com sorologia positiva não representa cão doente e que o teste utilizado neste 
inquérito sorológico, assim como qualquer outro desta natureza, não possui sensibilidade absoluta. Portanto não podemos descartar a possibilidade de que possam existir eventualmente cães falso-positivo neste grupo teste.

Nenhum cão com sorologia negativa para a ELISA conseguiu infectar flebótomos. Todos os 11 animais moravam no mesmo ambiente que aqueles com sorologia positiva. Entretanto observamos que uma grande parcela de cães infectados também pode apresentar ausência de sinais clínicos (ALENCAR \& CUNHA, 1963; BERRAHAL et al., 1996).

O acesso do flebótomo ao cão e o posterior repasto sangüíneo, parece estar relacionado com a concentração destes insetos por $\mathrm{m}^{3}$ na gaiola (exposição cabeça) e na tenda (exposição corpo todo). O volume da tenda $\left(2,592 \mathrm{~m}^{3}\right)$ é 40,5 vezes maior que o volume da gaiola $\left(0,064 \mathrm{~m}^{3}\right)$. Apesar de não ter sido medido o número de flebótomos fêmeas ingurgitadas, a facilidade de acesso à fonte de alimentação pode ter influenciado a eficiência do repasto. Chama atenção também o fato de que foi na região da cabeça (orelhas), o local onde encontramos um maior número de exulcerações. As primeiras experiências de infecção com flebótomos em cães levaram a pensar que somente os animais com lesões cutâneas aparentes poderiam infectar os insetos (PARROT et al., 1930). Posteriormente, ADLER \& THEODOR (1931) constataram que lesões ulcerosas, contaminadas por bactérias, não constituem fonte estável de infecção para os flebótomos e que estes se infectam em grande proporção, sugando a pele aparentemente sã ou as lesões não ulceradas.

Estudos sobre os fatores que contribuem para uma maior infectividade dos cães são poucos. Observamos em nosso estudo que cães com idade inferior a 3 anos de idade infectaram flebótomos com uma freqüência estatisticamente significativa. Dos 14 cães infectantes para a Lu. longipalpis, 13 eram cães com idade menor que 3 anos. Por outro lado, o cão infectante com idade superior a 3 anos conseguiu infectar um maior número de flebótomos, embora esta diferença não seja considerada estatisticamente significativa. FRANÇA-SILVA et al. (2003) verificaram em um estudo em Montes Claros, Minas Gerais, através de um inquérito sorológico, que a prevalência de cães infectados pela $L$. (L.) 
chagasi é maior em cães mais velhos, apesar do maior número de animais jovens ( $<3$ anos) que fazia parte da população canina $(75,4 \%)$. Uma possível interpretação para esta aparente discordância é que um exame sorológico positivo num hospedeiro mais velho seja um marcador de uma infecção crônica e/ou de reinfecções, e que a probabilidade de um hospedeiro ter uma infecção crônica e/ou reinfecções é diretamente proporcional ao tempo de exposição na área endêmica. Neste caso, se um cão portador de uma infecção crônica e/ou vítima de reinfecções é menos infectante para os flebótomos, concluímos que uma infecção crônica e/ou reinfecções confere aos cães uma menor competência como reservatório.

As características clínicas onicogrifose e emagrecimento mostraram ser as mais marcantes entre os cães deste estudo. Todos os 14 cães que apresentaram o sinal clínico onicogrifose eram soropositivos e de 22 que apresentaram emagrecimento, 21 eram soropositivos. Além disso, observamos que estes sinais também estão associados à infectividade e a um número maior de flebótomos infectados. A observação de sinais clínicos em cães associados à infecção sempre chamou a atenção dos pesquisadores a fim de determinar um marcador (MARZOCHI et al., 1985; VERÇOSA, et al., 2008). Por outro lado, outros sinais clássicos também descritos na literatura como exulceração, adinamia e alopecia não mostraram ser significativos neste estudo.

Raros foram os cães com sorologia negativa que apresentaram algum dos sinais clínicos já descritos anteriormente. Este dado consolida a importância dos sinais clínicos na determinação dos animais soropositivos.

Os cães incluídos neste estudo representam uma amostra aleatória que podem ser generalizados para populações similares. Esta amostra é oriunda de uma população onde sistematicamente são realizados exames sorológicos visando a eliminação de cães soropositivos.

\section{CONCLUSÃO}

Podemos inferir a importância do cão na epidemiologia da LV como fonte de infecção para o flebótomo. Existem evidências que um cão com uma 
CHAVES, M.M. et al. Avaliação do potencial reservatório do cão na Leishmaniose Visceral em dois municípios do Estado do Ceará. PUBVET, Londrina, V. 7, N. 15, Ed. 238, Art. 1568, Agosto, 2013. D.O.I.: http://dx.doi.org/10.22256/pubvet.v7n15.1568

sorologia positiva associada a emagrecimento, onicogrifose e idade igual ou inferior a 3 anos é o que apresenta a maior probabilidade de ser infectante para os vetores, e devem receber uma atenção especial do programa de controle. Assim, podemos evidenciar esses sinais como excelentes marcadores, colaborando para a importância dessas características no diagnóstico clínico da LVC.

\section{AGRADECIMENTOS}

À Fundação Nacional de Saúde-FUNASA e Universidade Federal do Ceará-UFC pelo apoio financeiro e logístico.

\section{REFERÊNCIAS BIBLIOGRÁFICAS}

ABRANCHES, P.; SILVA-PEREIRA, M.C.D.; CONCEIÇÃO-SILVA, F.M.; SANTOS-GOMES, G.M.; JANZ, J.G. Canine leishmaniasis: pathological and ecological factors influencing transmission of infection. Journal of Parasitology, v. 77, p. 557-561, 1991.

ADLER, S.; THEODOR, O. Skin infection in canine visceral leishmaniasis. British Medical Journal, v. 2, p. 1179, 1931.

ALENCAR, J.E.; CUNHA, R.V. Inquéritos sobre calazar canino no Ceará- novos resultados. Revista Brasileira de Malariologia e Doenças Tropicais, v. 15, p. 391-403, 1963.

ALMEIDA, M.A.O.; JESUS, E.E.V.; SOUSA-ATTA, M.L.B.; ALVES, L.C.; BERNE, M.E.A.; ATTA, A.M. Clinical and serological aspects of visceral leishmaniasis in Northeast Brazilian dogs naturally infected with Leishmania chagasi. Veterinary Parasitology, v. 127, p. 227-232, 2005.

ALMEIDA, A. B. P. F.; FARIA, R. P.; PIMENTEL, M. F. A.; DAHROUG, M. A. A.; TURBINO, N. C. M. R.; SOUSA, V. R.F. Inquérito soro epidemiológico de leishmaniose canina em áreas endêmicas de Cuiabá, Estado de Mato Grosso. Revista da Sociedade Brasileira de Medicina Tropical, v. 42, n. 2, p. 156-159, 2009.

BADARÓ, R.; REED, S.G.; BARRAL, A.; ORGE, G.; JONES, T.C. Evaluation of the micro enzymelinked immunosorbent assay (ELISA) for antibodies in american visceral leishmaniasis: antigen selection for detection of infection-specific responses. American Journal of Tropical Medicine and Hygiene, v. 35, p. 72-78, 1986.

BARBOSA, D.S.; ROCHA, A.L.; SANTANA, A.A.; SOUSA, C.S.F.; DIAS, R.A.; COSTA-JUNIOR, L.M.; ABREU-SILVA, A.L. Soroprevalência e variáveis epidemiológicas associadas à leishmaniose visceral canina em área endêmica no município de São Luís, Maranhão, Brasil. Revista Ciência Animal Brasileira, v. 11, n. 3, p. 653-659, 2010.

BERRAHAL, F.; MARY, C.; ROZE, M.; BERENGER, A.; ESCOFFIER, K.; LAMOUROUX, D.; DUNAN, S. Canine leishmaniasis: identification of asymptomatic carriers by polymerase chain reaction and immunoblotting. American Journal of Tropical Medicine and Hygiene, v. 55, n. 3, p. 273-277, 1996. 
BRAGA, M.D.; COELHO, I.C.B.; POMPEU, M.M.L.; EVANS, T.G.; MACAULLIFE, I.T.; TEIXEIRA, M.J.; LIMA, J.W. Control of canine visceral leishmaniasis: comparison of results from a rapid elimination program of serum-reactive dogs using an immunoenzyme assay and slower elimination of serum-reactive dogs using filter paper elution indirect immunofluorescence. Revista da Sociedade Brasileira de Medicina Tropical, v. 31, n. 5, p. 419-424, 1998.

CHAGAS, A.W. Criação de flebótomos e transmissão da leishmaniose visceral americana. Memórias do Instituto Oswaldo Cruz, v. 35, p. 327-333, 1940.

CIAMARELLA, P.; OLIVA, G.; DE LUNA, R.; GRADONI, L.; AMBROSIO, R; CORTESE, L.; SCALONE, A.; PERSECHINO, A. A retrospective clinical study of canine leishmaniasis in 150 dogs naturally infected by Leishmania infantum. Veterinary Record, v. 141, n. 21, p. 539-543, 1997.

DEANE, M.P.; DEANE, L.M. Infecção natural do Phlebotomus longipalpis por leptomonas, provavelmente de Leishmania donovani, em um foco de calazar, no Ceará. O Hospital, v. 45, n. 6, p. 697-702, 1954.

DEANE, L.M. Epidemiologia e profilaxia do calazar. Revista Brasileira de Malariologia e Doenças Tropicais, v. 10, p. 431-450, 1958.

DE PAULA, A.A.; DA SILVA, A.V.M.; FERNANDES, O.; JANSEN, A.M. The use of immunoblot analysis in the diagnosis of canine visceral leishmaniasis in an endemic area of Rio de Janeiro. Journal of Parasitology, v. 89, n. 4, p. 832-836, 2003.

EVANS, T.G; VASCONCELOS, I.A; LIMA, J.W; TEIXEIRA, J.M; MCAULLIFE, I.T; LOPES, U.G.; PEARSON, R.D.; VASCONCELOS, A.W. Canine visceral leishmaniasis in northeast Brazil: assessment of serodiagnostic methods. American Journal of Tropical Medicine and Hygiene, v. 42, p. 118-123, 1990.

FERREIRA, L.C.; DEANE, L.; MANGABEIRA FILHO, O. Infecção do Phlebotomus longipalpis pela Leishmania chagasi. O Hospital, v. 14, p. 2, 1938.

FRANÇA-SILVA, J.C; DA COSTA, R.T.; SIQUEIRA, A.M.; MACHADO-COELHO, G.L.; DA COSTA, C.A.; MAYRINK, W.; VIEIRA, E.P.; COSTA, J.S.; GENARO, O.; NASCIMENTO, E. Epidemiology of canine visceral leishmaniasis in the endemic area of Montes Claros Municipality, Minas Gerais State, Brazil. Veterinary Parasitology, v. 111, p. 161-173, 2003.

GONTIJO, C. M. F.; MELO, M. N. Leishmaniose visceral no Brasil: quadro atual, desafios e perspectivas. Revista Brasileira de Epidemiologia, v. 7, n. 3, p. 338-349, 2004.

GRADONI, L. Epizootiology of canine leishmaniasis in southern Europe. In: Proceedings of the International Canine Leishmaniasis Forum, 1999, Barcelona, Spain. Canine Leishmaniasis: an update. Hoescht Roussel Veterinary, p. 32-39, 1999.

GRADONI. L. The diagnosis of canine leishmaniasis. In: Proceedings of the Second International Canine Leishmaniasis Forum, 2002, Sevilla, Spain. Canine Leishmaniasis: moving towards a solution. Intervet International, p. 7-14, 2002.

GUARGA, J.L.; LUCIENTES, J.; PERIBAÑEZ, M.A.; MOLINA, R.; GRACIA, M.J.; CASTILLO, J.A. Experimental infection of Phlebotomus perniciosus and determination of the natural infection rates of Leishmania infantum in dogs. Acta Tropica, v. 77, p. 203-207, 2000.

KELLY, D.W. \& DYE, C. Pheromones, kairomones and the aggregation dynamics of the sandfly Lutzomyia longipalpis. Animal Behavior, v. 53, p. 721-731, 1997. 
KILLICK-KENDRICK, R.; LEANEY, A.J.; READY, P.D. The establishment, maintenance, and productivity of a laboratory colony of Lutzomyia longipalpis (Díptera: Psychodidae). Journal of Medical Entomology, v. 13, p. 429-440, 1977.

KILLICK-KENDRICK, R., KILLICK-KENDRICK, M. The initial establishment of sandfly colonies. Parasitologia, v. 33, p. 315-320, 1991.

LACERDA M.M. The Brazilian leishmaniasis control program. Memórias do Instituto Oswaldo Cruz, v.89, p. 489-495, 1994.

LANOTTE, G.; RIOUX, J.A.; PERIERES, J.; VOLLHARDT, Y. Ecologie des leishmanioses das le sud de la France, 10. Les formes evolutives de la leishmaniasis viscerale canine. Elaboration d'une typologie bio-clinique a finalité épidemiologique. Annales de Parasitologie Humaine et Compareé, v. 54, n. 3, p. 277-295, 1979.

LIMA, L.V.R.; CARNEIRO, L.A.; CAMPOS, M.B.; CHAGAS, E.J.; LAURENTI, M.D.; CORBETT, C.E.P.; LAINSON, L.; SILVEIRA, F.T. Canine visceral leishmaniasis due to Leihsmania (L.) infantum chagasi in Amazonian Brazil: comparison of the parasite sensity from the skin, lymph node and visceral tissues between symptomatic and asymptomatic, seropositives dogs. Revista do Instituto de Medicina Tropical de São Paulo, v. 52, n. 5, p. 259-265, 2010.

MAGALHÃES P.A.; MAYRINK W.; DA COSTA C.A.; MELO M.N.; DIAS M.; BATISTA S.M.; MICHALICK M.S.; WILLIAMS P. Kala-azar in the Rio Doce, Minas Gerais área. Results of prophylatic measures. Revista do Instituto de Medicina Tropical de São Paulo, v. 22, n. 4, p. $197-202,1980$.

MARZOCHI, M.C.A.; COUTINHO, S.G., SABROZA, P.C.; SOUSA, M.A.; SOUSA, P.P.; TOLEDO, L.M.; RANGEL FILHO, F.B. Leishmaniose visceral canina no Rio de Janeiro-Brasil. Cadernos de Saúde Pública, v.1, n. 4, p. 432-446, 1985.

MINISTÉRIO DA SAÚDE DO BRASIL. Secretaria de Vigilância em Saúde. Departamento de Vigilância Epidemiológica. Manual de vigilância e controle da Leishmaniose visceral. Brasília, DF; 2006. (Série A. Normas e Manuais Técnicos).

MOHAMMED, E.A.; WRIGHT, E.P.; KAGER, P.A.; LAARMAN, J.J.; PONDMAN, K.W. ELISA using intact promastigotes for immunodiagnosis of kala-azar. Transactions of the Royal Society of Tropical Medicine and Hygiene, v. 79, p. 344-50, 1985.

MOLINA, R.; AMELA, C.; NETO, J.; SAN-ANDRÉS, M.; GONZALES, F.; CASTILLO, J.A.; LUCIENTES, J.; ALVAR, J. Infectivity of dogs naturally infected with Leishmania infantum to colonized Phlebotomus perniciosus. Transactions of the Royal Society of Tropical Medicine and Hygiene, v. 88, p. 491-493, 1994.

MONTEIRO, O.S; LACERDA, M.M; ARIAS, J.R. Controle da leishmaniose visceral no Brasil. Revista da Sociedade Brasileira de Medicina Tropical, v. 27, n. 3, p. 67-72, 1994.

PALATNIK-DE-SOUSA, C.B.; DOS SANTOS, W.R.; FRANÇA-SILVA, J.C.; DA COSTA, R.T.; REIS, A.B.; PALATNIK, M.; MAYRINK, W.; GENARO, O. Impact of canine control on the epidemiology of canine and human visceral leishmaniasis in Brazil. American Journal of Tropical Medicine and Hygiene, v. 65, n. 5, p. 510-517, 2001.

PARROT, L; DONATIEN, A.; LESTOQUARD, F. Sur le development du parasite de la leishmaniose canine viscérale chez Phlebotomus major var. perniciosus Newstead. Bulletin de la Societe de Pathologie Exotique et de ses Filiales, v. 23, p. 724-726, 1930. 
POZIO, E.; GRANDONI, L.;, BETTINI, S.; , GRAMICCIA, M. Leishmaniasis in Tuscany (Italy): VI. Canine leishmaniasis in the focus of Monte Argentario (Grosseto). Acta Tropica, v. 38, n. 4, p. 383-393, 1981

SIDERIS, V.; PAPADOPOULOU, G.; DOTSIKA, E.; KARAGOUNI, E. Assymptomatic canine leishmaniasis in Greater Athens area, Greece. European Journal of Epidemiology, v. 15, $n$. 3, p. 271-276, 1999.

TRAVI, B.L.; TABARES, C.J.; CADENA, H.; FERRO, C.; OSORIO, Y. Canine visceral leishmaniasis in Colombia: relationship between clinical and parasitologic status and infectivity for sand flies. American Journal of Tropical Medicine and Hygiene, v. 64, n. 3-4, p. 119-124, 2001.

VERÇOSA, B.L.; LEMOS, C.M.; MENDONÇA, I.L.; SILVA, S.M.; DE CARVALHO, S.M.; GOTO, H.; COSTA, F.A. Transmission potential, skin inflammatory response, and parasitism of symptomatic and asymptomatic dogs with visceral leishmaniasis. BioMed Central Veterinary Research, $\mathrm{n}$. 4, p. 45, 2008. 